\title{
The modern Fontan operation shows no increase in mortality out to 20 years: A new paradigm
}

\author{
Robert J. Dabal, MD, ${ }^{\mathrm{a}}$ James K. Kirklin, MD, ${ }^{\mathrm{a}}$ Manisha Kukreja, MBBS, MPH, ${ }^{\mathrm{a}}$ Robert N. Brown, BS, ${ }^{\mathrm{a}}$ \\ David C. Cleveland, MD, ${ }^{a}$ Michael C. Eddins, MD, ${ }^{b}$ and Yung Lau, $\mathrm{MD}^{\mathrm{c}}$
}

\begin{abstract}
Objective: Dating back to the first published report of the Fontan circulation in 1971, multiple studies have examined the long-term results of this standard procedure for palliation of single-ventricle heart disease in children. Although the technique has evolved over the last 4 decades to include a polytetrafluorethylene (PTFE) conduit for a large percentage of patients, the long-term outcome has not yet been established. The aim of the current study was to investigate the possibility of a late increasing risk for death after 15 years among patients with a modern Fontan operation and to evaluate late morbidity.
\end{abstract}

Methods: Between January 1, 1988, and December 31, 2011, 207 patients underwent the Fontan procedure using an internal or external PTFE conduit plus a bidirectional cavopulmonary connection. Survival and late adverse events were analyzed. Risk factors for early and late mortality were examined using hazard function methodology.

Results: At 1, 10, and 20 years, survival for the entire cohort was $95 \%, 88 \%$, and $76 \%$, respectively, with no deaths in the last 6 years of the study. Hazard modeling showed a 1.3\% risk of death per year 24 years after the Fontan procedure, with no late increasing hazard phase. Freedom from reoperations was greater than $90 \%$ at 20 years and freedom from thrombotic complications was $98 \%$ at 20 years (with greater than $80 \%$ of patients on aspirin alone). Survival curves were superimposable for 16 - to $20-\mathrm{mm}$ conduits, and the freedom from any reoperation including transplantation was greater than $90 \%$ after 20 years. Multivariable risk factor analysis identified only earlier date of operation as a predictor of early and late mortality. By era of surgery, the 10 -year predicated survival is $89 \%$ for patients undergoing surgery in 2000 and $94 \%$ for patients in 2010 .

Conclusions: Early and late survival after a Fontan operation with a PTFE conduit is excellent, with no late phase of increasing death risk after 20 years. Late functional status is good, the need for late reoperation is rare, and thrombotic complications are uncommon on a standard medical regimen including aspirin as the only anticoagulation medication. (J Thorac Cardiovasc Surg 2014;148:2517-24)

See related commentary on page 2525 .

\section{Supplemental material is available online.}

Although little controversy exists over the success of the Fontan procedure in palliating infants with complex single-ventricle physiology, the late outcomes of this operation remain speculative. Dating to the publication of

\footnotetext{
From the Division of Cardiothoracic Surgery, ${ }^{\text {a }}$ Department of Surgery, School of Medicine, ${ }^{\mathrm{b}}$ and Division of Pediatric Cardiology, ${ }^{\mathrm{c}}$ Department of Pediatrics, University of Alabama at Birmingham, Birmingham, Ala.

Disclosures: Authors have nothing to disclose with regard to commercial support.

Read at the 94th Annual Meeting of The American Association for Thoracic Surgery, Toronto, Ontario, Canada, April 26-30, 2014.

Received for publication April 21, 2014; revisions received July 16, 2014; accepted for publication July 22, 2014; available ahead of print Sept 30, 2014.

Address for reprints: Robert J. Dabal, MD, Division of Cardiothoracic Surgery, University of Alabama, 176F, Suite 9100, 619 19th St S, Birmingham, AL 35249-0006 (E-mail: rdabal@uab.edu)

$0022-5223 / \$ 36.00$

Copyright (c) 2014 by The American Association for Thoracic Surgery http://dx.doi.org/10.1016/j.jtcvs.2014.07.075
}

the perfect Fontan operation article by Fontan and colleagues in $1990,{ }^{1}$ a late phase of increasing hazard has been postulated for these patients that predicts an increasing risk of death or the need for transplant after the first decade. We previously demonstrated the absence of a late increasing risk of death during the first decade using current surgical methods. ${ }^{2}$ The current analysis examines late outcomes after 20 years using a standard surgical technique.

\section{MATERIALS AND METHODS \\ Patient Population}

Between January 1, 1988, and December 31, 2011, 207 patients at the University of Alabama at Birmingham underwent a Fontan procedure using an extracardiac or intracardiac polytetrafluoroethylene (PTFE) tube, with a bidirectional cavopulmonary connection performed previously or during the same procedure. The last Fontan procedure not using a tube occurred in 1997; a PTFE tube has been used in all Fontan procedures since then The median age at operation was 4.6 years (range, 1.7-38 years). The morphologic subsets are listed in Table 1. Although most patients managed in a single ventricular pathway underwent a Fontan procedure, less than $20 \%$ of patients considered did not undergo a Fontan procedure because of several risk factors including significant unrepairable atrioventricular valve regurgitation, diminished ventricular function, and/or unfavorable pulmonary artery anatomy. ${ }^{2}$ 


\section{Abbreviations and Acronyms \\ NYHA $=$ New York Heart Association \\ PTFE = polytetrafluorethylene}

\section{Patient Follow-up}

The formal follow-up began on November 12, 2012. After obtaining appropriate approval from our Institutional Review Board, attempts were made to contact each of the 182 surviving patients using a standardized interview form pertaining to general condition, adverse events, and New York Heart Association (NYHA) class. All relevant medical records were reviewed for operative, follow-up, and adverse event information. After 3 failed attempts to contact each patient, the last documented medical encounter at the University of Alabama at Birmingham or elsewhere was used to obtain follow-up and adverse event information. Patients were censored at the time of last follow-up, and no patient was assumed to be alive past that point of documentation. The follow-up completeness index was $89 \%$. Follow-up was formally completed on February 28, 2013. Among all surviving patients, the median follow-up was 5.4 years, with a maximum of 22.8 years. The study period divided by era included 112 patients from 1988 to 2005 and 95 patients from 2006 to 2011.

\section{Adverse Events}

Documented arrhythmia was defined as any documented treatment of a disturbance of rhythm after initial hospitalization and/or recollection of such treatment by family members during a telephone interview.

Reoperations, including Fontan takedown, Fontan revision, cardiac transplantation, and additional cardiac procedures, were documented for each patient.

Thrombosis and thromboembolism included 2 subsets: first, any cardiac or extracardiac thromboembolic episode documented during follow-up; second, any episode of thrombosis within the PTFE tube or the Fontan pathway. All patients were routinely discharged on aspirin as the only anticoagulant unless there was a prior history of thromboembolic episodes, in which case warfarin was added. The addition of warfarin at the time of hospital discharge or during follow-up was documented for each patient.

\section{Surgical Strategy}

All patients were operated on through a median sternotomy using cardiopulmonary bypass with moderate hypothermia. All patients underwent a bidirectional cavopulmonary connection as part of the final reconstruction. Of the 207 patients, 164 (79\%) received the cavopulmonary connection at a previous operation. All fenestrations, when performed, were accomplished with a 4-mm punched hole in the PTFE tube.

\section{Statistical Analysis}

Nonparametric estimates of freedom from event and survival were obtained using the Kaplan-Meier method. $P$ values for stratified nonparametric comparisons were determined using the log-rank test.

Parametric estimates of freedom from death after completion of the Fontan procedure using PTFE tubes were obtained using multiphase hazard analysis in which the instantaneous risk (hazard) of death was estimated as a function of time. ${ }^{3}$ Parametric hazard analysis allows estimation of the instantaneous risk at each moment in time starting with time zero, which, for this study, was the time the Fontan procedure was performed. The 3 -phase hazard analysis identifies up to 3 separate but overlapping phases of hazard. The effect of risk factors is estimated by proportional hazards regression within each phase of hazard. To estimate the risk, we calculated

$$
L(t)=u_{1} g_{1}(t, x)+u_{2} g_{2}(t, x)=u_{3} g_{3}(t, x)
$$

where each $u$ is a $\log$-linear function of the hazard phase; $g_{1}, g_{2}$, and $g_{3}$ are shaping functions; $t$ is the time to event; and $x$ represents the risk factors.
Specific analyses examined the possible presence of an early, constant, and late increasing phase of risk with associated risk factors. The variables included in the multivariable analysis are listed in Appendix E1.

All statistics were performed using SAS software version 9.3 (SAS Institute, Inc, Cary, NC) in conjunction with custom software used for hazard analysis (for additional details, see http://www. clevelandclinic.org/heartcenter/hazard).

\section{RESULTS \\ Evolution of the Fontan Technique}

During this 24-year experience, a preliminary bidirectional cavopulmonary connection has been used almost exclusively since 1992. In the initial part of the experience, an internal PTFE $(n=61)$ tube was used to connect the inferior vena cava to the pulmonary arteries. External tube placement began in 1998 and since 2001 has been the uniform method of Fontan construction.

\section{Survival}

The 1-, 10-, and 20-year survival with the use of a PTFE tube was $95 \%, 88 \%$, and $77 \%$, respectively (Figure 1). A rapidly declining early risk phase merged with a constant phase at about 1 month. No late increasing phase of risk was identified after 20 years. The constant phase hazard function was calculated at $1.3 \% / y$ over the study period. Hospital mortality decreased from 7\% between 1988 and 1997 to $0 \%$ since 2005. Patients receiving a Fontan procedure in the earlier era (1988-1997) had inferior 10-year survival compared with the recent era (1998-2011) $(80 \%$ vs $92 \%, P=.009)$ (Figure 2). Causes of death are listed in Table 2.

\section{Size and Location of the PTFE Tube}

Most patients (146 of 207; 70\%) received an extracardiac tube, and $82 \%$ (169 of 207) of tubes were $16 \mathrm{~mm}$ in diameter (Table 3). Survival stratified by tube size (Figure 3) suggests optimal survival with a PTFE tube of $16 \mathrm{~mm}$ or larger.

\section{Fenestration}

A fenestration was performed at the time of the Fontan procedure in 94 of $207(45 \%)$ patients. Fenestration at the time of Fontan procedure was not associated with improved long-term survival $(P=.2)$. At the time of last follow-up, 28 of $74(38 \%)$ patients with complete data still had a fenestration. A total of $24(32 \%)$ patients underwent fenestration closure; $22(30 \%)$ patients had spontaneous closure.

\section{Reoperations After the Fontan Procedure}

A total of 15 reoperations were performed (Table 4). Freedom from any reoperation, including transplantation, was greater than $90 \%$ after 20 years for patients receiving a PTFE tube of $16 \mathrm{~mm}$ or larger (Figure 4). The Fontan revisions included 1 patient who required connection of an aberrant hepatic vein to the Fontan pathway, 2 patients 
TABLE 1. Cardiac morphology

\begin{tabular}{lcr}
\hline \multicolumn{1}{c}{ Morphology } & n & \% \\
\hline Tricuspid atresia & 59 & 29 \\
Double inlet left ventricle & 25 & 12 \\
Hypoplastic left heart syndrome & 18 & 9 \\
Complex double outlet right ventricle & 17 & 8 \\
Heterotaxy/discordant atrioventricular connections & 12 & 6 \\
Unbalanced atrioventricular septal defect & 12 & 6 \\
Pulmonary atresia/intact ventricular septum & 11 & 5 \\
Other single ventricle & 43 & 21 \\
Other complex congenital cardiac disease & 10 & 5 \\
Total & 207 & 100 \\
\hline
\end{tabular}

who required replacement of conduits from the hepatic veins to the pulmonary artery, 1 patient with conduit thrombosis whose conduit was relocated to the main pulmonary artery, and 1 patient who underwent division of the main pulmonary artery. The type of revision was unknown for 1 patient.

\section{Thromboembolic Events}

The standard protocol during this experience incorporated aspirin alone for anticoagulation (Table 5). Warfarin was added if specific indications existed. At last follow-up, $81 \%$ of patients were taking aspirin as the only anticoagulation medication (Table 6). The actuarial freedom from any thrombotic or thromboembolic event was $98 \%$ for each at 20 years.

\section{Arrhythmias}

The risk of arrhythmia (see Materials and Methods section for definition) was less with extracardiac tube placement (Figure 5). Freedom from documented

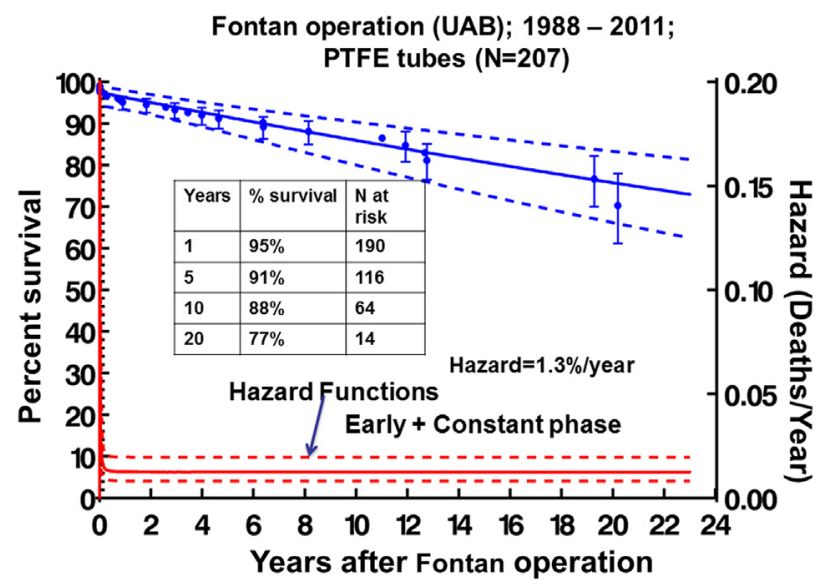

FIGURE 1. Actuarial and parametric survival after the Fontan operation using polytetrafluoroethylene (PTFE) tubes, the lower red line indicates the instantaneous risk (hazard) of death, in which the rapidly falling early phase merges with a constant phase within the first 3 months. The error bars represent $\pm 1 \mathrm{SE}$. The dashed lines enclose the $70 \%$ confidence limits. $U A B$, University of Alabama at Birmingham.
Fontan operation (UAB); 1988 - 2011; PTFE tubes ( $N=207$ )

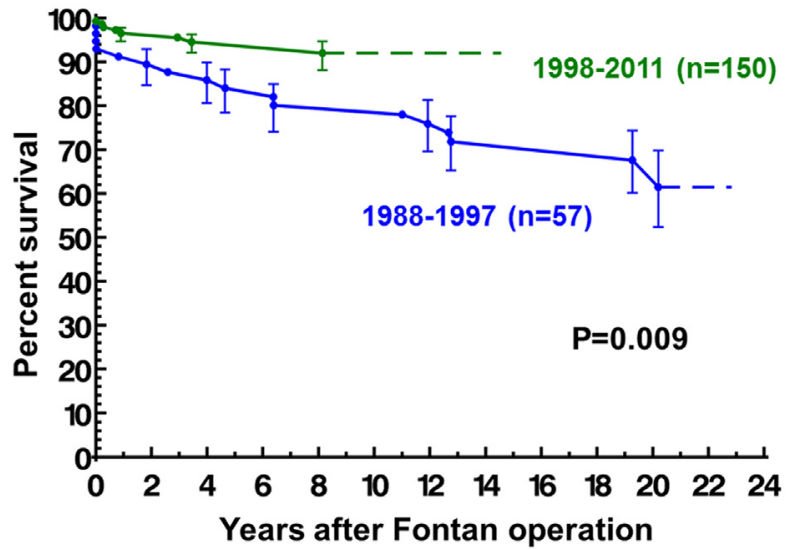

FIGURE 2. Actuarial survival after Fontan procedure, stratified by era of operations. Error bars represent $\pm 1 \mathrm{SE}$. $U A B$, University of Alabama at Birmingham; PTFE, polytetrafluoroethylene.

supraventricular arrhythmias was $73 \%$ at 10 years in the extracardiac PTFE group, and for any arrhythmia 71\%. Pacemaker implantation was required in 10 patients, 5 with external tubes and 5 with internal tubes.

\section{Functional State}

Most surviving patients were in NYHA class I or II at follow-up, even beyond 12 years (Figure 6). Less than $10 \%$ of patients were either in NYHA class III or unknown. By logistic regression, time since Fontan did not affect NYHA class $(P=.96)$.

\section{Risk Factor Analysis}

By multivariable analysis, earlier date of operation was the only risk factor identified in the early $(P=.04)$ and constant $(P=.02)$ phases. The effect was most evident during the 1990s decade, and the effect of operative date was absent after 1998. Solution of the multivariable equation indicated an expected 10-year survival of $94 \%$ for a patient receiving the Fontan operation in 2010 (Figure 7).

\section{DISCUSSION}

\section{Evolution of the Fontan Operation}

The Fontan operation has undergone significant evolution since its inception ${ }^{4}$ and since the classic analysis of

TABLE 2. Causes of death

\begin{tabular}{lcr}
\hline \multicolumn{1}{c}{ Cause of death } & $\mathbf{n}$ & $\%$ \\
\hline Early failed Fontan & 8 & 32 \\
Late failed Fontan & 8 & 32 \\
Cardiac arrest & 1 & 4 \\
Endocarditis & 1 & 4 \\
Stroke & 1 & 4 \\
Unknown & 6 & 24 \\
Total & 25 & 100 \\
\hline
\end{tabular}


TABLE 3. Tube sizes

\begin{tabular}{lccr}
\hline PTFE tube size $(\mathbf{m m})$ & Intracardiac $(\mathbf{n})$ & Extracardiac $(\mathbf{n})$ & Total \\
\hline 13 & 0 & 1 & 1 \\
14 & 4 & 2 & 6 \\
16 & 57 & 112 & 169 \\
18 & 0 & 13 & 13 \\
19 & 0 & 14 & 14 \\
20 & 0 & 4 & 4 \\
Total & 61 & 146 & 207 \\
\hline
\end{tabular}

PTFE, Polytetrafluoroethylene.

the perfect Fontan. ${ }^{1}$ During that era, common surgical options included right atrial appendage to a divided main pulmonary artery, ${ }^{5}$ right atrial appendage to right ventricular outflow tract (Bjork modification), ${ }^{6}$ and direct connection between the roof of the right atrium and the right pulmonary artery. The lateral tunnel was introduced later. ${ }^{7}$ The extracardiac conduit with disconnection of the inferior vena cava was described by Humes and Danielson ${ }^{8}$ and suggested as the technique of choice for all Fontan operations by Marcelletti. ${ }^{9}$ With the emphasis on streamlining blood flow through the Fontan pathway by DeLeval and others, ${ }^{10}$ we evolved to a practice of routine use of a PTFE tube by 1990. This evolution to a standardized technique led to the routine achievement of the perfect Fontan pathway based on our 2008 analysis. $^{2}$

\section{Survival}

The 1990 Fontan analysis of the perfect Fontan predicted a 15 -year survival of $73 \%{ }^{1}$ during an era in which a variety of surgical techniques were used. The improved survival with the PTFE tube technique provided 10-year survivals of $88 \%$ to $90 \%{ }^{2,11}$ The current analysis indicates

\section{Fontan Operation (UAB); 1988-2011; PTFE Tubes}

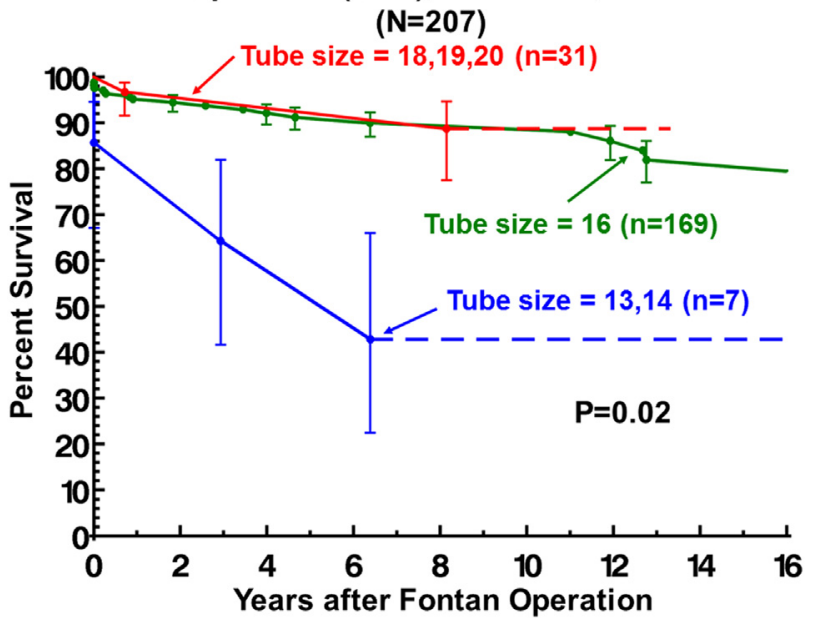

FIGURE 3. Actuarial survival after Fontan procedure, stratified by tube size. $U A B$, University of Alabama at Birmingham; PTFE, polytetrafluoroethylene.
TABLE 4. Reoperations after the Fontan

\begin{tabular}{lr} 
& Reoperations \\
\hline Fontan takedown & 5 \\
Fontan revision & 6 \\
Heart transplant & 1 \\
Resection of left ventricular outflow tract obstruction & 1 \\
Tricuspid replacement & 1 \\
Closure of aberrant hepatic vein & 1 \\
Total & 15 \\
\hline
\end{tabular}

ongoing improvement in survival over time, even among patients receiving an extracardiac tube. In the current era of pediatric cardiac surgery with improved management of patients after Fontan surgery, the projected survival for patients undergoing the extracardiac tube Fontan procedure has improved to $94 \%$ for a patient operated on in 2010. The current analysis suggests that an intracardiac Fontan procedure may be a better surgical option than a higher risk ventricular repair in certain patients whose repair includes considerable imponderables.

\section{Tube Size and Location}

The opportunity to further simplify the operation by avoiding cardiac ischemia was a stimulus to evolve from intracardiac to extracardiac tubes, which includes the option for implantation without cardiopulmonary bypass. ${ }^{11}$ Appropriate tube size remains a controversial issue. Although some have argued that a PTFE tube of $20 \mathrm{~mm}$ or greater is needed to allow for patient growth, ${ }^{12}$ our experience suggests that a 16-mm PTFE tube is adequate for the adult size patient. Furthermore, Itatani and colleagues ${ }^{13}$ have demonstrated superior flow characteristics with tubes of 16 or $18 \mathrm{~mm}$.

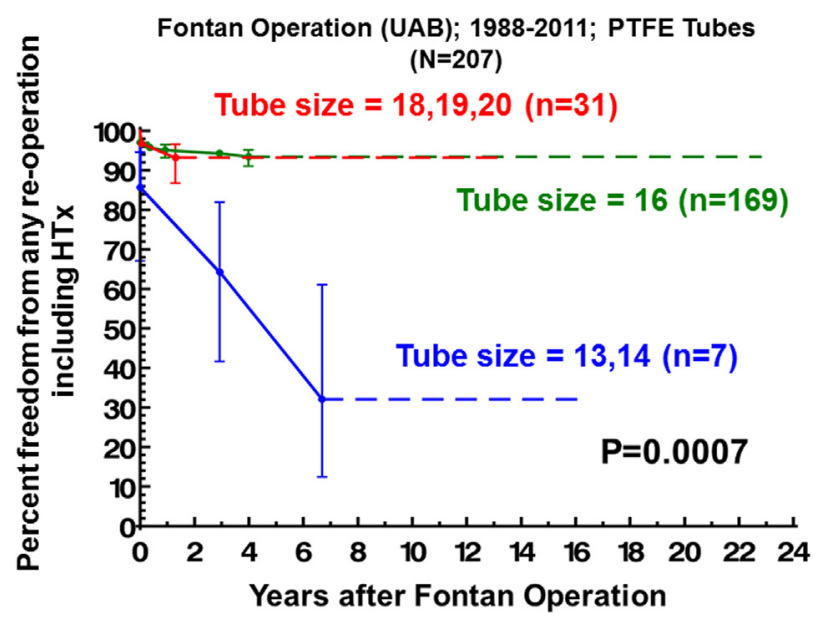

FIGURE 4. Freedom from reoperation, stratified by tube size. $U A B$, University of Alabama at Birmingham; PTFE, polytetrafluoroethylene; $H T x$, heart transplantation. 
TABLE 5. Anticoagulation medications at discharge

\begin{tabular}{lrr}
\hline Anticoagulation medications & n & \% \\
\hline None & 10 & 5 \\
Aspirin only & 165 & 82 \\
Coumadin only & 9 & 4 \\
Aspirin and warfarin & 14 & 7 \\
Other (dabigatran etexilate) & 1 & $<1$ \\
Unknown & 3 & 1 \\
Total & 202 & 100 \\
\hline
\end{tabular}

\section{Fenestrations}

In this experience, fenestration of the Fontan pathway was not used routinely, but rather selectively for patients perceived to be at higher risk of increased Fontan pathway pressures including patients with unfavorable pulmonary artery anatomy, those with significant atrioventricular valve regurgitation, and those with diminished function. Fenestrations were routinely accomplished with a 4-mm punch, although some have recommended a 5-mm hole for patients more than about $12 \mathrm{~kg} .{ }^{14}$ Fenestration did not confer a demonstrable survival advantage, but we cannot exclude the possibility that a fenestration may neutralize certain risk factors for early morbidity. ${ }^{15}$ Although controversy exists on the value of fenestration, ${ }^{16,17}$ recent practice reports indicate that fenestration is used in more than $50 \%$ of Fontan procedures in the United States. ${ }^{16}$

\section{Reoperations}

Late reoperations have been rare in this experience in which most patients received a 16-mm tube. In an era before the use of PTFE conduits, the risk of requiring reoperation for pathway obstruction gradually increased over time. This has not been the case with the use of PTFE tubes, in which late conduit obstruction is rare, ${ }^{11,17-20}$ and no late increasing hazard was identified in this experience after 20 years.

\section{Thromboembolic Event}

Thromboembolic complications before the recent era were reported among $5 \%$ to $16 \%$ of patients, ${ }^{24,26}$ often in the setting of stasis of flow in a markedly dilated right atrium. Possibly related to maintenance of laminar flow and reduced stasis with the extracardiac conduit and lateral

TABLE 6. Anticoagulation medications at follow-up

\begin{tabular}{lrr}
\hline Anticoagulation medications & $\mathbf{n}$ & $\%$ \\
\hline None & 22 & 12 \\
Aspirin only & 148 & 81 \\
Warfarin only & 6 & 3 \\
Aspirin and warfarin & 3 & 2 \\
Subcutaneous heparin & 1 & $<1$ \\
Unknown & 2 & 1 \\
Total & 182 & 100 \\
\hline
\end{tabular}

Fontan Operation; (UAB); 1988-2011; PTFE Tubes

$(\mathrm{N}=207)$

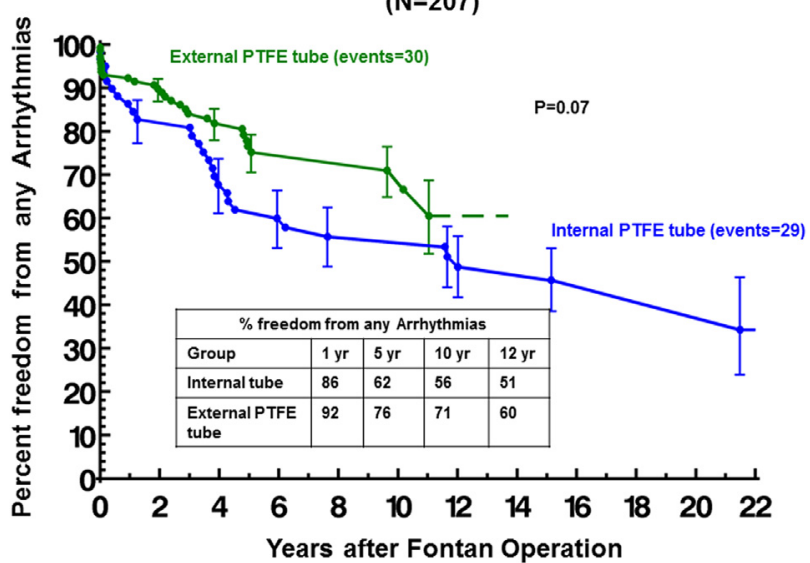

FIGURE 5. Freedom from arrhythmias, stratified by internal versus external PTFE tube. $U A B$, University of Alabama at Birmingham; PTFE, polytetrafluoroethylene.

tunnel approaches, this experience and others indicate a very low risk of thrombosis late after an extracardiac conduit Fontan procedure. ${ }^{2,11}$ The level of anticoagulation required to minimize thrombosis remains controversial, particularly the need for routine warfarin administration. This experience and our previous analysis ${ }^{2}$ support the routine use of aspirin, reserving warfarin for patients with documented risk factors for thromboembolic events.

\section{Rhythm Disturbances}

In this experience, supraventricular and overall rhythm disturbances were less common in patients receiving extracardiac versus intracardiac conduits. The advantages of avoiding a long atrial suture line is supported by clinical $^{11,27}$ and experimental ${ }^{28,29}$ studies, which show greater preservation of sinus rhythm and lower incidence of supraventricular arrhythmias with an extracardiac tube versus the lateral tunnel.

\section{Functional State}

Before the construction of streamlined pathways, functional status was noted to gradually decline over time. ${ }^{2}$ In this experience, the proportion of patients in NYHA class I has remained quite stable for a 15 -year interval from the time of surgery; 100 patients have reached that interval. In addition, almost patients regardless of interval of follow-up remain highly functional. Others have reported that patients with lateral tunnel or extracardiac conduits (see Results section) have better functional outcomes than with previous Fontan techniques, but exercise capacity remains well below normal. ${ }^{21-23}$ At least 1 multicenter study suggests better functional outcomes with extracardiac conduits compared with a lateral tunnel. ${ }^{24}$ It has been hypothesized that improved late functional outcomes relate to more preserved ventricular 


\section{Fontan Operation (UAB); 1988-2011; PTFE Tubes ( $\mathrm{N}=207$ )}

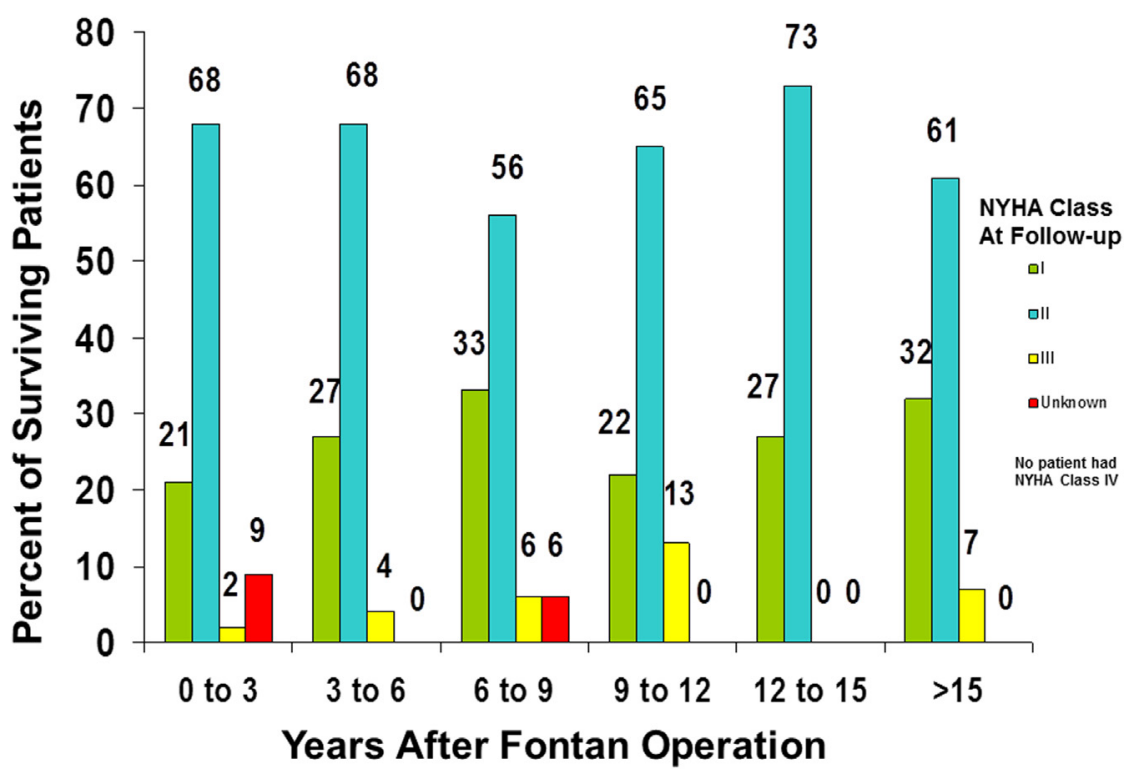

FIGURE 6. Percentage of patients in specified NYHA classes at the indicated follow-up intervals after the Fontan operation. UAB, University of Alabama at Birmingham; PTFE, polytetrafluoroethylene; NYHA, New York Heart Association.

function caused by the absence of increased coronary sinus pressure (by draining the coronary sinus into the low-pressure atrium) and avoidance of myocardial ischemia during the repair. ${ }^{25}$

\section{Limitations}

The current study is limited primarily because it represents experience in a single institution and is retrospective in nature. The patient population, although encompassing

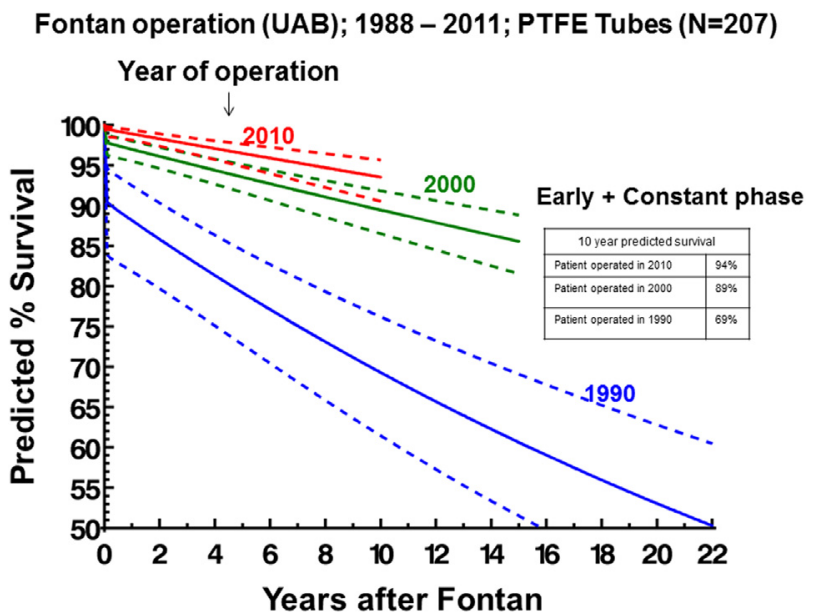

FIGURE 7. Nomogram of a solution to the multivariable risk factor equation for survival after Fontan. Solutions are depicted for Fontan procedures performed in 1990, 2000, and 2010. Dashed lines enclose the $90 \%$ confidence limits. $U A B$, University of Alabama at Birmingham; PTFE, polytetrafluoroethylene. all common single-ventricle conditions, is somewhat biased because of a relatively small percentage of patients with a hypoplastic left heart, who are only represented in the last decade of the experience. Patients with hypoplastic left heart syndrome were underrepresented in the study population because Norwood procedures were not performed at the study institution until the later in the study period. Future analysis of this cohort with longer follow-up will be necessary and will include a larger percentage of patients with hypoplastic left heart syndrome. The current literature, however, is mixed with regard to the effect of single ventricular morphology on Fontan outcomes although several studies suggest that outcomes with systemic right ventricles are equivalent to systemic left ventricles. ${ }^{14,16}$ Although the current study does not show a late increasing hazard after 20 years, further follow-up may lead to the characterization of such a phase beyond 25 years or more.

\section{CONCLUSIONS}

A standardized Fontan operation using a $16-\mathrm{mm}$ or greater extracardiac conduit and a bidirectional cavopulmonary connection offers excellent long-term survival, freedom from reoperation, and good functional state. For the first time, the absence of a late increasing phase of risk has been documented after at least 20 years.

\section{References}

1. Fontan F, Kirklin JW, Fernandez G, Costa F, Naftel DC, Tritto F, et al. Outcome after a "perfect" Fontan operation. Circulation. 1990;81:1520-36. 
2. Kirklin JK, Brown RN, Bryant AS, Naftel DC, Colvin EV, Pearce FB, et al. Is the "perfect Fontan" operation routinely achievable in the modern era? Cardiol Young. 2008; 18:328-36.

3. Blackstone EH, Naftel DC, Tirner ME. The decomposition of time-varying hazard into phases, each incorporating a separate stream of concomitant information. J Am Statistical Assoc. 1986;81:615-24.

4. Fontan F, Baudet E. Surgical repair of tricuspid atresia. Thorax. 1971;26:240-8.

5. Fontan F, Mounicot FB, Baudet E, Simonneau J, Gordo J, Gouffrant JM. "Correction" de l'atresie tricuspidienne. Rapport de deux cas "corriges" par l'utilisation d'une technique chirurgicale nouvelle. Ann Chir Thorac Cardiovasc. 1971;10:39-47.

6. Bjork VO, Olin CL, Bjarke BB, Thoren CA. Right atrial-right ventricular anastomosis for correction of tricuspid atresia. J Thorac Cardiovasc Surg. $1979 ; 77: 452-8$

7. Lemier MS, Ramaciotti C, Stromberg D, Scott WA, Leonard SR. The extracardiac lateral tunnel Fontan, constructed with bovine pericardium: comparison with the extracardiac conduit Fontan. Am Heart J. 2006;151:928-33.

8. Humes RA, Feldt RH, Porter CJ, Julsrud PR, Puga FJ, Danielson GK. The modified Fontan operation for asplenia and polysplenia syndromes. J Thorac Cardiovasc Surg. 1988;96:212-8.

9. Marcelletti C, Corno A, Giannico S, Marino B. Inferior vena cavapulmonary artery extracardiac conduit. J Thorac Cardiovasc Surg. 1990;100:228-32.

10. de Leval MR, Kilner P, Gewillig M, Bull C. Total cavopulmonary connection: a logical alternative to atriopulmonary connection for complex Fontan operations. J Thorac Cardiovasc Surg. 1988;96:682-95.

11. Petrossian E, Reddy VM, Collins KK, Culbertson CB, MacDonald MJ, Lamberti JJ, et al. The extracardiac conduit Fontan operation using minimal approach extracorporeal circulation: early and midterm outcomes. J Thorac Cardiovasc Surg. 2006;132:1054-63.

12. Alexi-Meskishvili V, Ovroutski S, Ewert P, Dahnert I, Berger F, Lange PE, et al. Optimal conduit size for extracardiac Fontan operation. Eur J Cardiothorac Surg. 2000;18:690-5.

13. Itatani K, Miyaji K, Tomoyasu T, Nakahata Y, Ohara K, Takamoto S, et al. Optimal conduit size for extracardiac Fontan operation based on energy loss and flow stagnation. Ann Thorac Surg. 2009;88:565-73.

14. Kopf GS, Kleinman CS, Hijazi ZM, Fahey JT, Dewar MI, Hellenbrand WE. Fenestrated Fontan operation with delayed transcatheter closure of atrial septal defect: improved results in high-risk patients. J Thorac Cardiovasc Surg. 1992; 103:1039-47.

15. Geva T, Ott DA, Ludomirsky A, Argyle SJ, O'Laughlin MP. Tricuspid atresia associated with aortopulmonary window: controlling pulmonary blood flow with a fenestrated patch. Am Heart J. 1992;123:260-2.

16. Tweddell JS, Nersesian M, Mussatto KA, Nugent M, Simpson P, Mitchell ME, et al. Fontan palliation in the modern era: factors impacting mortality and morbidity. Ann Thorac Surg. 2009;88:1291-9.

17. Fiore AC, Tan C, Aarmbrecht E, Huddleston CB, Kim E, Goel N, et al. Comparison of fenestrated and nonfenestrated patients undergoing extracardiac Fontan. Ann Thorac Surg. 2014;97:924-31.

18. Jaquiss RD, Imamura M. Single ventricle physiology: surgical options, indications and outcomes. Curr Opin Cardiol. 2009;24:113-8.

19. Lee C, Lee CH, Hwang SW, Lim HG, Kim SJ, Lee JY, et al. Midterm followup of the status of Gore-Tex graft after extracardiac conduit Fontan procedure. Eur Cardiothorac Surg. 2007:31:1008-12.

20. Ochiai Y, Imoto Y, Sakamoto M, Kajiwara T, Sese A, Watanabe M, et al. Midterm followup of the status of Gore-Tex graft after extracardiac conduit Fontan procedure. Eur J Cardiothorac Surg. 2009;36:63-8.

21. Muller J, Christov F, Schreiber C, Hess J, Hager A. Exercise capacity, quality of life, and daily activity in the long term followup of patients with univentricular heart and total cavopulmonary connection. Eur Heart J. 2009;30:2915-20.

22. Rigby ML, Gibson DG, Joseph MC, Lincoln JC, Shinebourne EA, Shore DF, et al. Recognition of imperforate atrioventricular valves by two-dimensional echocardiography. Br Heart J. 1982;47:329-36.

23. Yin Z, Wang C, Zhu H, Zhang R, Wang H, Li X. Exercise tolerance in extracardiac total cavopulmonary connection. Asian Cardiovasc Thorac Surg. 2009; 17:39-45

24. Anderson PA, Sleeper LA, Mahony I, Colan SD, Atz AM, Breitbart RE, et al. Contemporary outcomes after the Fontan procedure: a Pediatric Heart Network multicenter study. J Am Coll Cardiol. 2008;52:86-98.

25. Ilbawi MN, Idriss FS, Muster AJ, DeLeon SY, Berry TE, Duffy CE, et al. Effects of elevated coronary sinus pressure on left ventricular function after the Fontan operation. J Thorac Cardiovasc Surg. 1986;92:231-7.
26. Jacobs MI, Pourmoghadam KK. Thromboembolism and the role of anticoagulation in the Fontan patient. Pediatr Cardiol. 2007;28:457-64.

27. Petrossian E, Reddy VM, McElhinney DB, Akkersdijk GP, Moore P, Parry AJ, et al. Early results of the extracardiac conduit Fontan operation. J Thorac Cardiovasc Surg. 1999;117:688-96.

28. Balaji S, Case CL, Sade RM, Gillette PC. Arrhythmias and electrocardiographic changes after the hemi-Fontan procedure. Am J Cardiol. 1994;73:828-9.

29. Gandhi SK, Bromberg BI, Rodefeld MD, Schuessler RB, Boineau JP, Cox JL, et al. Lateral tunnel suture line variation reduces atrial flutter after the modified Fontan operation. Ann Thorac Surg. 1996;61:1299-309.

\section{Discussion}

Dr Harold M. Burkhart (Oklahoma City, Okla). Dr Dabal and colleagues from the University of Alabama continue their quest for the perfect Fontan in their most recent series update. They present a 25-year Fontan experience involving more than 200 patients with excellent survival and an extremely low risk of reoperation. Of note, they demonstrate no increasing phase of risk after 20 years. Congratulations on the excellent results and the very nice presentation.

I have 3 questions.

First, we all know that picking the perfect patient is the first step to a perfect Fontan result. Could you please discuss your current exclusion criteria for offering a Fontan operation; specifically, where do atrioventricular valve regurgitation, ventricular dysfunction, and marginal pulmonary architecture fit in? What percentage of your patients initially planned for the Fontan pathways are ultimately denied the operation?

Dr Dabal. Thank you for your comments and thank you for your questions. The first question is an excellent one. If you look at our series and you look at the last publication from our institution on our Fontan results, the percentage of patients that do not ultimately end up with a Fontan palliation who initially begin on that pathway is in the neighborhood of $15 \%$. And I think that you have mentioned the main reasons why patients do not make it: decreased cardiac function; unfavorable pulmonary vasculature or high pulmonary artery pressures; significant atrioventricular valve regurgitation. Those are probably the 3 biggest factors that would preclude us from performing a Fontan.

Dr Burkhart. My second question is along the same lines as the first question. I note, as you noted, $10 \%$ of your patients, or less than, had hypoplastic left heart syndrome and they have a lot of the problems that we discussed earlier in the exclusion criteria. Given that most large series typically have a higher proportion, could you first explain why yours does not have that proportion; and furthermore, do you think that if you did have that proportion your results would be different?

Dr Dabal. So the hypoplastic population is definitely only represented in the latter part of our experience. Until about 2005, those patients were not having Norwoods in Alabama, so that is why they are somewhat underrepresented in the population.

Based on our multivariable analysis, however, morphology did not make any difference in survival. It was not a risk factor for mortality. I think that certainly as we get increasing length of follow-up this may change, but I think that there are plenty of data out there to suggest from multiple institutions that ventricular morphology is not necessarily a risk factor for poor late-term outcomes. 
Dr Burkhart. And my final question is a technical one. I note that the average age of Fontan in your group is almost 5 years; however, the most common conduit size is $16 \mathrm{~mm}$. As you know, some have argued for larger conduits especially in larger patients. Would you please discuss your current approach to and reasoning behind your conduit choice.

Dr Dabal. Well, I think that the conduit choice has been a personal preference, but it is borne out by the literature. If you look at a lot of the computational analyses of flow characteristics of 16-mm tubes, it has been shown that those are preferable to larger tubes in terms of lower risk of stasis and risk of thrombosis related to that stasis. I think that our experience has been somewhat skewed by the era effect. If you look at the latter era, our median age of operation is probably significantly lower than 4.6 years, probably closer to the 2- to 3 -year age range. And the bottom line is a $16-\mathrm{mm}$ conduit is almost always easily put into a child at that size. Our long-term results have shown that it really does not make much difference, that the results are as good or better with a $16-\mathrm{mm}$ tube as they are with an $18-$ or $20-\mathrm{mm}$ tube, and so that is our logic for doing that.

Dr Sertac M. Cicek (Istanbul, Turkey). Congratulations on the excellent results. You stated that almost $50 \%$ of the patients had a fenestration, $45 \%$ exactly. What are your indications for fenestration? This is a significantly high incidence of fenestration for such a group of patients.

Dr Dabal. Thank you for the question. I think that that is another factor that has changed significantly over the experience at the University of Alabama at Birmingham. Earlier in the experience there was routine fenestration for most patients; however, over the last 5 to 10 years we have been much more selective with our application of fenestrations. Currently, our indications are similar to what we would consider to be high-risk Fontans. So any patient who has decreased function, a significant amount of atrioventricular valve regurgitation, or unfavorable pulmonary artery anatomy, those are the 3 categories of patients that we would consider fenestrating.

Dr Jennifer Hirsch-Romano (Ann Arbor, Mich). When you performed your era analysis, what was the decision making for the year that you chose to separate the 2 groups into the 2 eras?

Dr Dabal. I think we basically split it down the middle.

Dr Hirsch-Romano. Was there a change in surgical technique or management strategy at that time?

Dr Dabal. No, there really was not. The only significant change during the period was the transition from intracardiac to extracardiac tubes, but there was no change really in the middle or latter part of the study period.

Dr Hillel Laks (Los Angeles, Calif). I enjoyed your talk very much. I would just caution about the $16-\mathrm{mm}$ graft. In our experience we have had 1 reoperation for a $16-\mathrm{mm}$ graft and this was in a female who was quite tall. It occurred when she was adult size, about $1.7 \mathrm{~m}$ tall. But this was a patient who had a fenestration that was subsequently closed with an Amplatzer device, and potentially the addition of some added encroachment on the lumen made a difference; she had about a 5-mm gradient across it. So I would say that we now prefer always using an $18-\mathrm{mm}$ or a $20-\mathrm{mm}$ graft wherever possible. But in younger children, sometimes it is difficult to get a $16-\mathrm{mm}$ graft into a 3 -year-old who is small; in that case it may be worthwhile waiting longer until the child is bigger, and particularly if it is a boy with large parents and you are expecting that child to become quite large. I think that a 16-mm graft in a full-size adult with a big body surface area is going to be inadequate and it is worthwhile trying to put a larger graft in.

Dr Dabal. Thank you for your comment.

Dr Carl L. Backer (Chicago, Ill). Apropos the presentations here on Saturday morning where we discussed extracardiac Fontan versus lateral tunnel; it seems that your paper is a very nice addition to the literature supporting extracardiac Fontan. I want to take the opportunity to survey this very august group. How many surgeons primarily use the extracardiac Fontan approach when they do a Fontan operation?

(Show of hands.)

All right. How many surgeons use the lateral tunnel?

(Show of hands.)

It looks like you have now convinced a few more surgeons. For the primary Fontan, it looked to me that about $80 \%$ of surgeons are doing extracardiac and $20 \%$ are doing the lateral tunnel.

The second thing I noticed in your study was that $81 \%$ of your patients are on aspirin, which has been our institutional strategy. I would like to survey this group; how many are keeping their patients solely on aspirin after the Fontan operation?

(Show of hands.)

It looks like a pretty sizable number of hands.

And how many are on warfarin?

(Show of hands.)

My read on this is that about $70 \%$ of people are putting their patient on aspirin after a Fontan operation and maybe $25 \%$ to $30 \%$ on warfarin. 
APPENDIX E1. VARIABLES ENTERED IN THE MULTIVARIABLE RISK MODEL FOR DEATH

Age at operation

Date of operation

Gender and ethnicity

Morphologic type

Fenestration at Fontan

Internal versus external tube

Size of tube graft

Previous cavopulmonary connection 